\title{
Indicators of the metabolic syndrome in obese adolescents
}

\author{
Moushira Erfan Zaki ${ }^{1}$, Hala T. El-Bassyouni², Mona El-Gammal², Sanaa Kamal ${ }^{1}$
}

\author{
${ }^{1}$ Biological Anthropology Department, Medical Research Division, National Research \\ Centre, Giza, Cairo, Egypt \\ ${ }^{2}$ Clinical Genetics Department, Human Genetics and Genome Research Division, \\ National Research Centre, Giza, Cairo, Egypt
}

Submitted: 25 January 2013

Accepted: 4 April 2013

Arch Med Sci 2015; 11, 1: 92-98

DOI: 10.5114/aoms.2015.49214

Copyright $\odot 2015$ Termedia \& Banach

\section{Abstract}

Introduction: To assess the prevalence of metabolic risk indicators for the metabolic syndrome (MS) in a sample of obese Egyptian adolescents and to compare anthropometric and biochemical parameters in subjects with one or two parameters of the MS with those who meet MS criteria.

Material and methods: A descriptive, cross-sectional study was conducted on 300 obese adolescents, with a mean age of $15.45 \pm 2.54$ years. Variables examined included body mass index (BMI), waist circumference (WC), waist to hip ratio (WHR), systolic and diastolic blood pressure (BP), fasting blood glucose, cholesterol, triglycerides (TG), high-density lipoprotein (HDL), low-density lipoproteins (LDL), insulin and insulin resistance (IR) measured by Homeostasis Model Assessment-Insulin Resistance (HOMA-IR). Receiver operating characteristic (ROC) curve analysis was used to determine the predictive powers of anthropometric parameters associated with increased risk for the MS.

Results: The overall prevalence of the MS was 20\%. Individuals meeting 3 or more MS criteria had significantly higher levels of BP, TG, glucose, insulin and HOMA-R and low HDL levels compared with those who had 1 or 2 MS criteria. Area under the curve (AUC) for identifying the MS risk factors was the highest for WHR, followed by WC and BMI in both genders $(p<0.001)$. Conclusions: The most prevalent metabolic risk factors that compose the MS were arterial hypertension, low HDL and hypertriglyceridemia; BMI tended to be the weakest index for identifying MS risk factors, while WHR was the best predictive index in both genders.

Key words: obesity, metabolic risk factors, adolescents, anthropometry.

\section{Introduction}

Obesity in children and adolescents is a major public health problem which is increasing worldwide, thus increasing the likelihood of the metabolic syndrome (MS). Metabolic syndrome is essentially considered as a product of an interaction between multiple genetic and environmental factors, though its pathogenesis is not clearly determined. Metabolic syndrome is defined as a clustering of interrelated metabolic risk factors that increase the risk of cardiovascular morbidity and mortality [1]. These factors include insulin resistance or glucose intolerance, central/abdominal obesity, hypertension and dyslipidemia, particularly decreased

\author{
Corresponding author: \\ Moushira Erfan Zaki \\ Biological Anthropology \\ Department \\ Medical Research Division \\ National Research Centre \\ Giza, Cairo, Egypt \\ El Buhouth St., Dokki, \\ Cairo, Egypt \\ 12311 Cairo, Egypt \\ Phone: (+202) 33371362 \\ Fax: (+202) 33370931 \\ E-mail: \\ moushiraz@yahoo.com
}


high-density lipoprotein cholesterol (HDL-C) and hypertriglyceridemia [2]. Insulin resistance and leptin may be important pathogenic factors in hypertensive patients with severe obesity [3]. The prevalence of the MS varies among different populations. A remarkably high prevalence of the MS has been reported in Western communities, Asians, Africans and in Arabs [4, 5]. The recorded high prevalence of the MS and its key cardiovascular risk factors (15-60\%) among the Middle East population mandates the need for national and international prevention programs to combat MS [6]. The criteria for diagnosis of the MS include obesity (particularly increased waist circumference (WC)), high fasting triglycerides, low levels of HDL-C, hypertension, elevated fasting blood glucose and insulin resistance [7-9]. Homeostasis Model Assessment-Insulin Resistance (HOMA-IR) is an indirect marker of insulin resistance [10]. Lack of congruent diagnostic criteria has resulted in reporting of variable prevalence of the disease in different studies [11]. For example, the thresholds of the WC diagnostic of abdominal obesity in most studies are derived from European data [8]. There is a need to develop national guidelines for the definition of abdominal obesity. This study is an attempt to highlight the usefulness of the proxy markers of the MS focusing on a sample of obese Egyptian adolescents.

The aim of this study is to assess indicators of the MS and evaluate the prevalence of the different components of the MS in individuals meeting 1 or 2 MS criteria with those who meet 3 or more MS criteria.

\section{Material and methods}

A descriptive cross-sectional study was conducted on 300 obese adolescents with body mass index $(\mathrm{BMI})$ greater than the $97^{\text {th }}$ percentile for age and gender according to the National Egyptian Growth Curves of Children and Adolescents [12]. One hundred and twenty males (40\%) and 180 females $(60 \%)$ were included, of mean age $15.45 \pm 2.54$ years (range: $17-21$ years). The data were collected from June 2011 to July 2012 and were extracted from a project entitled "Obesity among Youth: Lifestyle and Genetic Factors" funded by the Science and Technology Development Fund (STDF), Egypt. This study protocol was approved by the ethical committee board of the National Research Centre of Egypt (No. 10/223). Informed written consent was obtained from all participants. All individuals were clinically evaluated and anthropometric data were collected. The components of the MS that were observed are WC, body mass index (BMI), impaired blood glucose, HDL, systolic and diastolic blood pressure (BP), hypertriglyceridemia, cholesterol and insulin resistance measured by HOMA. Metabolic syndrome was diagnosed by the occurrence of 3 or more of the following risk factors according to the 2007 International Diabetes Federation (IDF) [13]: WC greater than the $90^{\text {th }}$ percentile for age and gender, TG $\geq 150 \mathrm{mg} / \mathrm{dl}, \mathrm{HDL}<40 \mathrm{mg} / \mathrm{dl}$, BP $\geq 130 / 85$, basal blood glucose $\geq 100 \mathrm{mg} / \mathrm{dl}$. Weight was measured with the patients in light clothing and without shoes. Height was measured with the patients standing with their backs leaning against the stadiometer of the same scale. Body mass index was calculated as weight in kilograms divided by height in meters squared $\left(\mathrm{kg} / \mathrm{m}^{2}\right)$. Waist circumference and hip circumference $(\mathrm{HC})$ were measured in $\mathrm{cm}$ using a plastic, non-stretchable tailor's tape. Waist circumference was measured with light clothing at a level midway between the lower rib margin and the iliac crest standing and breathing normally. Hip circumference was measured at the level of the widest circumference over the buttocks (at the greater trochanter). Subsequently the waist hip ratio (WHR) was calculated as WC divided by HC. Blood pressure was measured with the patients sitting with their left arm at heart level using a professional Riester sphygmomanometer manufactured in Japan. Several measurements were made, from which an average BP measurement was obtained. Laboratory tests were performed with patients fasting for $12 \mathrm{~h}$. All the subjects underwent plasma glucose and HOMA-IR, which was calculated using relevant formulae. Normal fasting blood glucose was defined as levels ranging from $60 \mathrm{mg} / \mathrm{dl}$ to $100 \mathrm{mg} / \mathrm{dl}$; HOMA-IR greater than 3.5 was considered as pathological [10].

This study was performed according to the Helsinki declaration and was approved by the Ethical Research Committee of the National Research Centre, Egypt.

\section{Statistical analysis}

SPSS 16.0 software was used for statistical analysis. Quantitative variables were given as mean and standard deviation, and dichotomous variables as a percentage. Quantitative variables from patients with or without prediabetes were compared using Student's t-test for independent samples. A value of $p<0.05$ was considered statistically significant. Receiver operating characteristic (ROC) curve analyses was used to calculate the area under ROC curves between MS risk factors and anthropometric measurements. Each value of an anthropometric index was used as a cutoff value to calculate its sensitivity (defined as the percentage of subjects having MS risk) and specificity (defined as the percentage of subjects without MS risk) in predicting MS risk factors, after adjusting for age. The optimal cutoff value was 


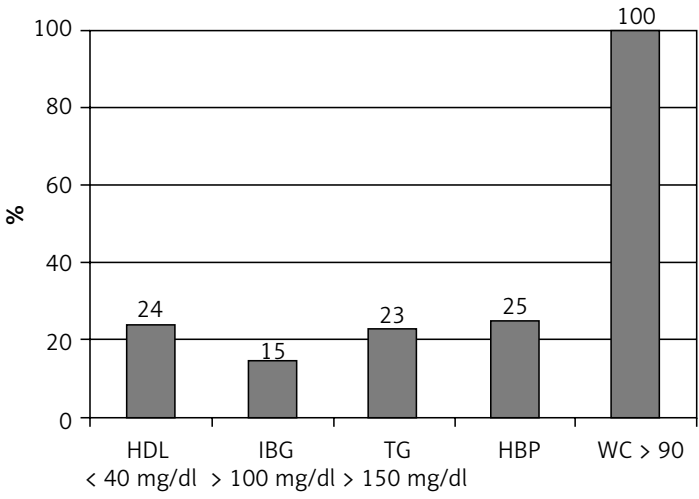

Figure 1. Prevalence of different components of the metabolic syndrome in the study sample

denoted by the Youden index, which is the value that had the highest sum of sensitivity and specificity [14]. A plot of the sensitivity versus 1 - specificity was used to display the trade-off between true positives and false positives across discriminating cutoff points.

\section{Results}

The prevalence of the MS according to the IDF criteria in the total sample of obese adolescents was $20 \%(60 / 300)$. Males and females were analyzed together because homogeneity of the effect was observed by gender. They presented 2 or more features of the MS (hypertension, obesity, dyslipidemia and altered glucose tolerance). Metabolic syndrome was more common in females $(22.2 \%$, $40 / 180)$ than in males $(16.6 \%, 20 / 120)$, with no statistically significant difference. The prevalence of the different components of the MS based on IDF criteria is shown in Figure 1. Table I shows a comparison of anthropometric, clinical and biochemical data in obese adolescents with 1 or 2 MS criteria and those with complete MS. The results showed that patients with the MS had significant- ly elevated values of blood glucose, BP (systolic and diastolic), TG and insulin resistance, and $\mathrm{HO}$ MA-IR, and a decreased value of HDL-C. The area under the receiver operating characteristic curve (and 95\% confidence interval) for BMI was 0.711 (0.597-0.825) and 0.740 (0.610-0.869); for WC 0.809 (0.741-0.877) and 0.829 (0.742-0.915); for WHR 0.834 (0.770-0.899) and 0.833 (0.7530.913 ) in females and males respectively, Figure 2 (females), Figure 3 (males) and Table II.

\section{Discussion}

The prevalence of obesity is increasing substantially, and obesity is one of the major contributors to the incidence of various diseases due to its pathophysiological link to other cardiovascular risks such as hypertension and diabetes [15]. The predominant underlying risk factors for the MS appear to be abdominal obesity, insulin resistance and other associated conditions that can be physical inactivity, aging, and hormonal imbalance [16]. Central obesity is characterized by increased visceral adipose tissue and appears to contribute more to the development of MS risk than general adiposity [17]. Presence of one or more metabolic abnormalities among obese subjects can be attributed to a sedentary lifestyle and dietary habits, which are important predictors of obesity and metabolic abnormalities. Central adiposity is an important indicator of the MS due to its link to dyslipidemia, hyperinsulinemia, hypertension, and impaired fibrinolytic capacity [18]. The phenotype of obesity varies in different ethnic groups [19]. As compared to white Caucasians, adult Asian Indians have lower height, weight, BMI, WC, and fat free mass, but higher body fat and abdominal adiposity [20]. A quarter of the world's adults have the MS [21]. People with the MS have a five-fold greater risk of developing type 2 dia-

Table I. Comparison of anthropometric, clinical and biochemical data

\begin{tabular}{|c|c|c|}
\hline Variables & 1 or 2 MS parameters & MS parameters $(\geq 3)$ \\
\hline Systolic blood [mm Hg] & $113.06 \pm 12.89$ & $126.32^{\star \star} \pm 15.44$ \\
\hline Diastolic blood pressure [mm Hg] & $73.96 \pm 8.65$ & $81.76^{\star *} \pm 12.18$ \\
\hline Glucose $[\mathrm{mg} / \mathrm{dl}]$ & $92.30 \pm 13.10$ & $105.12^{\star *} \pm 40.70$ \\
\hline Cholesterol [mg/dl] & $187.18 \pm 46.40$ & $192.76 \pm 46.96$ \\
\hline Triglycerides [mg/dl] & $90.28 \pm 37.10$ & $147.71^{* *} \pm 81.65$ \\
\hline $\mathrm{HDL}-\mathrm{C}[\mathrm{mg} / \mathrm{dl}]$ & $56.60 \pm 17.88$ & $41.41^{\star \star} \pm 17.81$ \\
\hline LDL-C [mg/dl] & $115.68 \pm 38.87$ & $119.64 \pm 36.10$ \\
\hline Insulin $[\mu \mathrm{IU} / \mathrm{ml}]$ & $39.81 \pm 26.99$ & $75.00^{* *} \pm 37.86$ \\
\hline HOMA-IR & $9.57 \pm 7.34$ & $19.65^{* *} \pm 10.00$ \\
\hline
\end{tabular}

HDL-C - high-density lipoprotein cholesterol, LDL-C - low-density lipoprotein cholesterol, HOMA-IR - homeostasis model assessment for insulin resistance, MS - metabolic syndrome; ${ }^{* *} p<0.01$. 


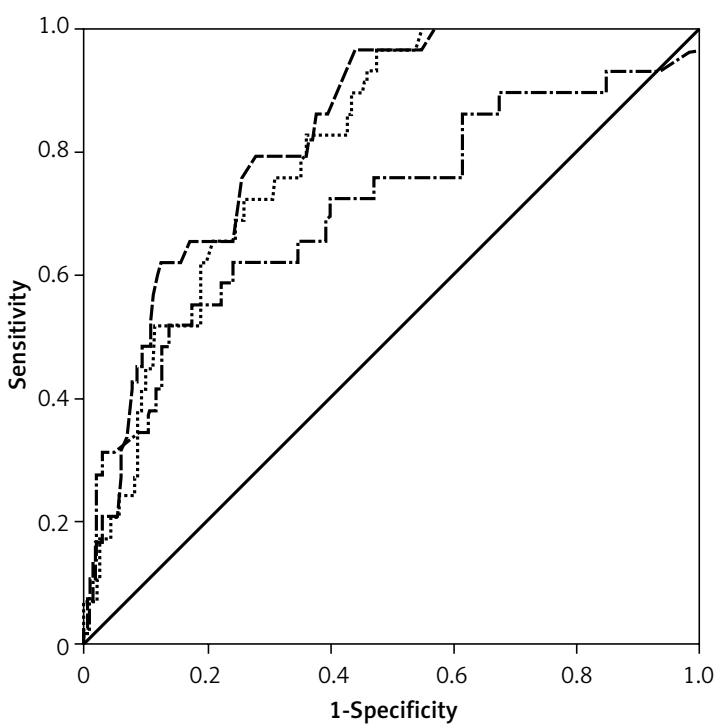

Source of the curve:

--- Waist to hip ratio ........ Waist circumference

-.- BMI $\longrightarrow$ Reference line

Figure 2. Receiver operating characteristic curves (ROC) for identifying the risk of metabolic syndrome in females

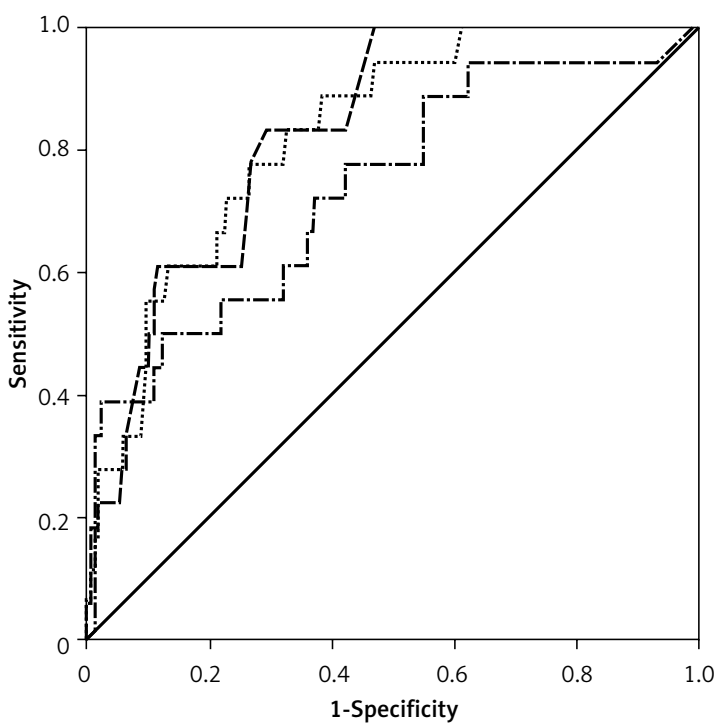

Source of the curve:

- -- Waist to hip ratio ........ Waist circumference

-- BMI - Reference line

Figure 3. Receiver operating characteristic curves (ROC) for identifying the risk of metabolic syndrome in males

Table II. Area under receiver operating characteristic curves for identifying the risk of metabolic syndrome by obesity indices

\begin{tabular}{|lccc|}
\hline Gender & $\begin{array}{c}\text { Body mass index }\left[\mathrm{kg} / \mathrm{m}^{2}\right] \\
(\mathbf{9 5 \%} \text { confidence intervals })\end{array}$ & $\begin{array}{c}\text { Waist circumference }[\mathrm{cm}] \\
(\mathbf{9 5 \%} \text { confidence intervals })\end{array}$ & $\begin{array}{c}\text { Waist to hip ratio } \\
(95 \% \text { confidence intervals })\end{array}$ \\
\hline Female & $0.711(0.597-0.825)$ & $0.809(0.741-0.877)$ & $0.834(0.770-0.899)$ \\
\hline Male & $0.740(0.610-0.869)$ & $0.829(0.742-0.915)$ & $0.833(0.753-0.913)$ \\
\hline
\end{tabular}

betes [22]. People have become more sedentary and consume more calories through non-healthy fast foods, leading to increased incidence of the MS. In our study, MS prevalence was $20 \%$. Other studies have reported similar MS prevalence rates ranging from $10 \%$ to $21 \%[1,23,24]$. More than one-third of the adults in the United States could be characterized as having the MS [25]. The prevalence of this syndrome is $19 \%$ in Mongolia, $21 \%$ in Jordan, $17 \%$ in Palestine $[5,6], 24.2 \%$ in Malaysia, $21.17 \%$ in Taiwan, $12.2 \%$ in Singapore, $12 \%$ in Japan, $14.8 \%$ in China, $28.8 \%$ in India, and $28.6 \%$ and $27.8 \%$, respectively, in male and female Koreans [26]. The prevalence of the MS in Iranian subjects aged 25 to 30 years was $35.9 \%$. Another study reported that prevalence of the MS reaches $50 \%$ in severely obese youngsters [4]. The current literature data suggest that the incidence of the MS is increasing rapidly all over the world, but its prevalence varies among populations [27, 28]. Our results are in accordance with some of these studies. Differences in population characteristics and dietary habits may be considered as the main sources of this variation. According to the area under the curves (AUCS) in our study, the
BMI was the weakest index compared with other obesity indices for MS diagnosis in both genders. Waist hip ratio was better than WC and BMI for predicting the MS risk in both genders. Although different studies agreed upon the five metabolic risk factors that compose the MS, they basically differ with respect to the diagnosis of central obesity $[1,13]$. Waist circumference and WHR are important indicators of central obesity and were independently associated with three MS components (HDL-C, TG, and SBP). Therefore, WC and WHR are stronger indicators of abdominal obesity and development of the MS. Waist hip ratio is so far the most widely used index of central fat distribution due to its benefits in routine monitoring and assessment in patients. Studies in Europeans [29], Asians [30], Africans [10], and Arab communities [31] were done by using ROC analysis to compare the performance of obesity indices for identifying such risks. Our results are in agreement with some of these studies [32-34]. Metabolic syndrome increased with age but increased even more dramatically as BMI increased [35]. In our study the MS was more common in females $(22.2 \%, 40 / 180)$ than males $(16.6 \%, 20 / 120)$, but 
without a statistically significant difference. In the adult population in Tehran the MS was found in $55 \%$ of women and $30.1 \%$ of men [4]. The overall prevalence of obesity in the Middle East region was considerably higher among women compared with men [6]. Although the exact explanation of such gender variations is not entirely clear, it has been reported that women are less active compared with men in certain areas [23]. Physical and cultural barriers to physical activity have been reported among women in Egypt and Saudi Arabia. These include climatic conditions of extreme heat in the summer, limited exercise facilities devoted solely for women, lack of physical education or an emphasis on its importance in schools, and absence of women's participation in organized sports [23]. The most prevalent component of the MS in our study was elevated WC, because all our patients were obese. Impaired blood glucose (IBG) was present in $15 \%$ of studied individuals, as insulin resistance is an obesity-related condition that plays a major pathogenic role in the development of the MS. The prevalence of IBG in previous studies was much lower (8.3\%) [36-38]. By contrast, insulin resistance was identified in $70 \%$ of obese prepubertal children in a study conducted in Lebanon [23]. However, the cumulative risk for the MS appears to cause microvascular dysfunction, which further amplifies insulin resistance and promotes hypertension $[39,40]$. Hypertension is an important cardiovascular disease (CVD) risk factor with high global prevalence. It is one of the most commonly identified components of the MS [15]. When hypertension and other metabolic risk factors co-exist in an individual, they potentiate one another, leading to a synergism that increases the total CVD risk well above that which results from the sum of the individual risk factors. Accordingly, MS risk factors should be quantified so that the type and intensity of treatment can be tailored to the degree of MS component risk factors [41]. Different results may be explained by differences in age, dietary habits, genetic or other factors. In our study, the prevalence of low HDL-C was $24 \%$. Insulin resistance may contribute to increased TG levels and may be responsible for decreased $\mathrm{HDL}-\mathrm{C}$ levels through an increase in the extent of apolipoprotein A1 (ApoA1)/HDL-C degradation as compared to its synthesis [42-44]. High BP found in $25 \%$ of observed obese individuals is similar to previous studies $[3,45]$. An additional study conducted in Iran reported high BP in $48.9 \%$ of individuals over 19 years old [25]. Hypertriglyceridemia was present in $23 \%$ of individuals observed in our study. High serum TG was found in $28.6 \%$ of a French population and $42.8 \%$ of an Iranian population [25]. Finally, it should be noted that prevention and early management of the differ- ent MS components in childhood and adolescence are of utmost importance. Efforts should be aimed at preventing obesity, initiating and maintaining healthy eating patterns, and encouraging moderate intensity regular physical activity.

In conclusion, high prevalence of the MS was detected in obese Egyptian adolescents. The present results are in accordance with some Western and Arab studies [5, 6, 29]. The prevalence of the MS varied in the different studies due to lack of congruent diagnosis. Moreover, this study indicates that WHR could be the best predictive index for identifying MS risk in both genders, while BMI tends to be the weakest index. A meta-analysis of 10 studies in different populations (Europeans, Asians, and Africans) also showed the weakness of $\mathrm{BMI}$ as a discriminator [46-48]. Differences between populations could depend on several factors such as genetic variables, race, nutritional status, different socioeconomic-cultural characteristics and also lifestyle differences [49-53].

\section{Acknowledgments}

The authors are greatly thankful to the Science and Technology Development Fund (STDF) for funding the project entitled "Obesity among Youth: Lifestyle and Genetic Factors" (1225) that enabled us to use the data to establish this work.

\section{Conflict of interest}

The authors declare no conflict of interest.

\section{References}

1. Stepien M, Stepien A, Wlazel RN, et al. Predictors of insulin resistance in patients with obesity: a pilot study. Angiology 2014; 65: 22-30.

2. Rizzo AC, Goldberg TB, Silva CC, et al. Metabolic syndrome risk factors in overweight, obese, and extremely obese brazilian adolescents. Nutr J 2013; 12: 19.

3. Stępień M, Wlazeł RN, Paradowski M, et al. Serum concentrations of adiponectin, leptin, resistin, ghrelin and insulin and their association with obesity indices in obese normo- and hypertensive patients - pilot study. Arch Med Sci 2012; 8: 431-6.

4. Hekmatdoost A, Mirmiran P, Hosseini-Esfahani F, Azizi F. Dietary fatty acid composition and metabolic syndrome in Tehranian adults. Nutrition 2011; 27: 1002-7.

5. Al-Odat AZ, Ahmad MN, Haddad FH. References of anthropometric indices of central obesity and metabolic syndrome in Jordanian men and women. Diabetes Metab Syndr 2012; 6: 15-21.

6. Sliem HA, Ahmed S, Nemr N, El-Sherif I. Metabolic syndrome in the Middle East. Indian J Endocrinol Metab 2012; 16: 67-71.

7. Misra A, Khurana L, Vikram NK, et al. Metabolic syndrome in children: current issues and South Asian perspective. Nutrition 2007; 23: 895-91.

8. Pacifico L, Anania C, Martino F, et al. Management of metabolic syndrome in children and adolescents. Nutr Metab Cardiovasc Dis 2011; 21: 455-66. 
9. Magnussen CG, Koskinen J, Juonala M, et al. A diagnosis of the metabolic syndrome in youth that resolves by adult life is associated with a normalization of high carotid intima-media thickness and type 2 diabetes mellitus risk: the Bogalusa heart and cardiovascular risk in young Finns studies. J Am Coll Cardiol 2012; 60: 1631-9.

10. Kruger HS, Faber M, Schutte AE, Ellis SM. A proposed cutoff point of waist-to-height ratio for metabolic risk in African township adolescents. Nutrition 2013; 29: 502-7.

11. Lear SA, James PT, Ko GT, Kumanyika S. Appropriateness of waist circumference and waist-to-hip ratio cutoffs for different ethnic groups. Eur J Clin Nutr 2010; 64: 42-61.

12. Ghalli I, Salah N, Hussien F, et al. Egyptian growth curves 2002 for infants, children and adolescents. Sartorio A, Buckler JMH, Marazzi N (eds.). 2008.

13. International Diabetes Federation. Worldwide definition of the metabolic syndrome. Available at: http://www. idf.org/webdata/docs/MetSyndrome_FINAL.pdf. Accessed 19/05/2012.

14. Anthony A. Understanding diagnostic tests 3: receiver operating characteristic curves. Acta Paediatrica 2007; 96: 644-7.

15. World Health Organization, Global Health Risks: Mortality and burden of disease attributable to selected major risk. World Health Organization, Geneva, Switzerland, 2009.

16. Gupta N, Shah P, Nayyar S, Misra A. Childhood obesity and the metabolic syndrome in developing countries. Indian J Pediatr 2013; 80 Suppl. 1: S28-37.

17. Lamarche B. Abdominal obesity and its metabolic complications: implications for the risk of ischaemic heart disease. Coron Artery Dis 1998; 9: 473-81.

18. Carr Darcy B, Utzschneider Kristina M, Hull Rebecca L, et al. Intra-abdominal fat is a major determinant of the National Cholesterol Education Program Adult Treatment Panel III Criteria for the Metabolic Syndrome. Diabetes 2004; 53: 2087-94.

19. Fitzpatrick SL, Lai BS, Brancati FL, et al. Metabolic syndrome risk profiles among african american adoles cents: national health and nutrition examination survey, 2003-2010. Diabetes Care 2013; 36: 436-42.

20. Shiwaku K, Nogi A, Kitajima K, et al. Prevalence of the metabolic syndrome using the modified ATP III definitions for workers in Japan, Korea and Mongolia. J Occup Health 2005; 47: 126-35.

21. Moore SC, Gunter MJ, Daniel CR, et al. Common genetic variants and central adiposity among Asian-Indians. Obesity (Silver Spring) 2012; 20: 1902-8.

22. Jaber LA, Brown MB, Hammad A, et al. The prevalence of the metabolic syndrome among Arab Americans. Diabetes Care 2004; 27: 234-8.

23. Nasreddine L, Ouaijan K, Mansour M, et al. Metabolic syndrome and insulin resistance in obese prepubertal children in Lebanon: a primary health concern. Ann Nutr Metab 2010; 57: 135-42.

24. Kim MH, Kim MK, Choi BY, Shin YJ. Prevalence of metabolic syndrome and its association with cardiovascular disease in Korea. J Korean Med Sci 2004; 19: 195-201.

25. Azimi-Nezhad M, Herbeth B, Siest G, et al. High prevalence of metabolic syndrome in Iran in comparison with France: what are the components that explain this? Metab Syndr Relat Disord 2012; 10: 181-8.

26. Tan CE, Ma S, Wai D, et al. Can we apply the National Cholesterol Education Program Adult Treatment Pane definition of the metabolic syndrome to Asians? Diabetes Care 2004; 27: 1182-6.
27. Grundy SM, Brewer HB, Cleeman JI, et al. National Heart and Blood Institute, American Heart Association. Definition of metabolic syndrome: report of the National Heart, Lung and Blood Institute/American Heart Association conference on scientific issues related to definition. Circulation 2004; 109: 433-8.

28. Saberi HR, Moravveji AR, Fakharian E, et al. Prevalence of metabolic syndrome in bus and truck drivers in Kashan, Iran. Diabetol Metab Syndr 2011; 3: 8.

29. Lee MY, Huxley RR, Wildman RP, Woodward M. Indices of abdominal obesityare better discriminators of cardiovascular risk factors than BMI: a metaanalysis. J Clin Epidemiol 2008; 61: 646-53.

30. Can AS, Yıldız EA, Samur G, et al. Optimal waist: height ratio cut-off point for cardiometabolic risk factors in Turkish adults. Public Health Nutrition 2010; 13: 488-95.

31. Chedid R, Gannage-Yared MH, Khalife S, et al. Impact of different metabolic syndrome classifications on the metabolic syndrome prevalence in a young Middle Eastern population. Metabolism 2009; 58: 746-52.

32. Bouguerra R, Alberti $H$, Smida $H$, et al. Waist circumference cut-off points for identification of abdominal obesity among the Tunisian adult population. Diabetes Obes Metab 2009; 9: 859-68.

33. Khader YS, Batieha A, Jaddou H, et al. Anthropometric cut-off values for detecting metabolic abnormalities in Jordanian adults. Diabetes Metab Syndr Obes 2010; 3: 395-402.

34. Mirrakhimov AE, Lunegova OS, Kerimkulova AS, et al. Cut off values for abdominal obesity as a criterion of metabolic syndrome in an ethnic Kyrgyz population (Central Asian region). Cardiovasc Diabetol 2012; 11: 16.

35. Barzin M, Asghari G, Hosseinpanah F, et al. The association of anthropometric indices in adolescence with the occurrence of the metabolic syndrome in early adulthood: Tehran Lipid and Glucose Study (TLGS). Pediatr Obes 2013; 8: 170-7.

36. Agirbasli M, Agaoglu NB, Ergonul O, et al. Comparison of anthropometric indices in predicting metabolic syndrome components in children. Metab Syndr Relat Disord 2011; 9: 453-9.

37. Johnson WD, Kroon YJM, Greenway FL, et al. Prevalence of risks factors for metabolic syndrome in adolescents. Arch Pediatr Adolesc Med 2009; 163: 371-7.

38. Ten S, Maclaren N. Insulin resistance syndrome in children. J Clin Endocrinol Metab 2004; 89: 2526-39.

39. Love-Osborne K, Nadeau K, Sheeder J, et al. Presence of the metabolic syndrome in obese adolescents predicts impaired glucose tolerance and non-alcoholic fatty liver disease. J Adolesc Health 2008; 42: 543-8.

40. Lee J, Ma S, Heng D, et al. Should central obesity be an optional or essential component of the metabolic syndrome? Ischemic heart disease risk in the Singapore Cardiovascular Cohort Study. Diabetes Care 2007; 30: 343-7.

41. Ford ES, Giles WH, Dietz WH. Prevalence of the metabolic syndrome among US adult: findings from the Third National Health and Nutrition Examination Survey. JAMA 2002; 287: 356-9.

42. Kyriazis I, Rekleiti $M$, Saridi $M$, et al. Prevalence of obesity in children aged 6-12 years in Greece: nutritional behaviour and physical activity. Arch Med Sci 2012; 8: 859-64.

43. Wang S, Peng D. Regulation of adipocyte autophagy the potential anti-obesity mechanism of high density lipoprotein and apolipoprotein A-I. Lipids Health Dis 2012; 11: 131. 
44. Ismail NA, Ragab S, El Dayem SM, et al. Fetuin-A levels in obesity: differences in relation to metabolic syndrome and correlation with clinical and laboratory variables. Arch Med Sci 2012; 8: 826-33.

45. Guijarro de Armas MA, Monereo Megías S, Merino Viveros $M$, et al. Prevalence of metabolic syndrome in a population of obese children and adolescents. Endocrinol Nutr 2012; 59: 155-9.

46. Lee CM, Huxley RR, Wildman RP, Woodward M. Indices of abdominal obesity are better discriminators of cardiovascular risk factors than BMI: a meta-analysis. J Clin Epidemiol 2008; 61: 646-53.

47. Weili $Y$, He B, Yao $\mathrm{H}$, et al. Waist-to-height ratio is an accurate and easier index for evaluating obesity in children and adolescents. Obesity (Silver Spring) 2007; 15 748-52.

48. Stepien M, Rosniak-Bak K, Paradowski M, et al. Waist circumference, ghrelin and selected adipose tissue-derived adipokines as predictors of insulin resistance in obese patients: preliminary results. Med Sci Monit 2011; 17: PR13-8.

49. Karakaş P, Bozkır MG. Anthropometric indices in relation to overweight and obesity among Turkish medical students. Arch Med Sci 2012; 8: 209-13.

50. Nikolic D, Cvjeticanin S, Petronic I, et al. Population genetic analyses of susceptibility to increased body weight. Arch Med Sci 2012; 8: 998-1002.

51. Gundogan K, Bayram F, Gedik V, et al. Metabolic syndrome prevalence according to ATP III and IDF criteria and related factors in Turkish adults. Arch Med Sci 2013 9: 243-53.

52. Januszek-Trzciąkowska A, Małecka-Tendera E, Klimek K, Matusik P. Obesity risk factors in a representative group of Polish prepubertal children. Arch Med Sci 2014; 10: 880-5.

53. Rahmanian M, Kelishadi R, Qorbani M, et al. Dual burden of body weight among Iranian children and adolescents in 2003 and 2010: the CASPIAN-III study. Arch Med Sci 2014; 10: 96-103. 